\title{
Did Elitists Really Believe in Social Laws? Some Epistemological Challenges in the Work of Gaetano Mosca and Vilfredo Pareto
}

\author{
Marco Di Giulio $^{1}$ (D)
}

Accepted: 4 September 2021 / Published online: 11 October 2021

(c) The Author(s) 2021

\begin{abstract}
The epistemological standards of contemporary social sciences refute 'functional' and 'law-like' explanations, whereas mechanism-based causal explanations have become widely accepted in various fields of inquiry. The paper supports the hypothesis that authors Vilfredo Pareto and Gaetano Mosca, despite their deference to positivist epistemology, significantly anticipated these developments. Indeed, with their emphasis on history, contexts and agents, elitists ushered into the debate of their time some arguments that realist epistemology fully developed, emphasising the role of context-specific and, often, not directly observable explanatory features. To illustrate the ante litteram epistemological realism of elitist thinkers, the paper reconstructs the positions of Mosca and Pareto concerning two major themes of that time, in which elitists challenged the mainstream ideas and values of most of their peers with epistemological arguments that refuse a linear notion of causality.
\end{abstract}

Keywords Elitists · Epistemology $\cdot$ Epistemological realism $\cdot$ Mechanisms $\cdot$ Vilfredo Pareto $\cdot$ Gaetano Mosca

\section{Introduction}

Elitist thinkers, in particular Vilfredo Pareto and Gaetano Mosca, were part of the positivist movement in the socialsciences debate across the nineteenth and the early twentieth centuries (Croce 1923; Bobbio 2001; Hirschman 1991). Most importantly, they thought of themselves that way, albeit with peculiar nuances and caveats. Despite their faith in the existence of social law and the possibility of discovering it, elitists' social and political thought anticipated some post-positivistic stances that would fully emerge decades later in the social sciences.

In the recent literature, only Albert Bouvier (2012) argues that Pareto was the precursor of 'middle-range theories' in the social sciences, thanks to his attempt to focus on belief formation. From this perspective, this paper advances two claims. First, I argue that Gaetano Mosca shares the same epistemological stance. Second, and more importantly, elitist originality relies not simply on a different account of psychological attitudes but also on the attempt to understand the aggregate causality of individual behaviours and their

Marco Di Giulio

marco.digiulio@unige.it

1 Dipartimento di Scienze Politiche, Università di Genova, Piazzale E. Brignole, 3A, 16124 Genova, GE, Italy change over time. With their emphasis on history, contexts and agents, elitists ushered into the debate of their time some arguments that the current debate on 'mechanisms', understood as circumscribed, context-specific and, often, not directly observable explanatory features, fully developed (Elster 1960, 1989; Hedström and Swedberg 1996; Pawson and Tilley 1997; Panebianco 2009).

The paper is structured as follows. Relying on the contemporary debate on the epistemology of the social sciences, section two advances the contention that a significant part of elitists' causal arguments is more coherent with a realist rather than a positivist epistemology. To support such a claim, the following sections provide evidence from the work of Vilfredo Pareto and Gaetano Mosca. Pareto's thought received relatively more attention because it was far more advanced, in terms of epistemological and methodological terms, than that of other thinkers. Nonetheless, I will show how such interpretative claims derived from Pareto's epistemology are also valid for Mosca.

More specifically, section three argues that the main building blocks of Pareto's sociology, such as the concepts of 'residues' and 'derivations' or his understanding of 'interdependences', did anticipate some of the cornerstones of realist epistemology. In the same manner, Mosca's conception of political development tends to be critical with some positivistic stances, mostly assuming a linear evolution. To 
illustrate the ante litteram epistemological realism of elitist thinkers, sections four and five reconstruct the positions of Mosca and Pareto on two major themes of that time. The first concerns nationalism and racial theories, mostly based on Mosca's remarks on this debate. Then, section four focuses on Pareto's understanding of successful economic and industrial policy. In retrospect, these two issues are important because they represent two crucial debates of the time, in which Pareto and Mosca challenged the mainstream ideas and values of most of their peers, out of epistemological arguments denying the determinism of positivism.

\section{Disentangling Epistemology from Ontology}

The research question of this paper is abductively derived from Alfred O. Hirschman's The Rhetoric of Reaction (1991). Here, the economist argues that Pareto and Mosca use arguments based on the positivist idea of the existence of social laws, to demonstrate the futility of any attempt to introduce liberal reforms. Such a sharp assessment surely grasps some attitudes of the two thinkers-especially considering their critique of socialism-but it also misses two deeper foundations of their thought. One concerns their stances towards democracy which, despite criticism of the institutions of their times, have been recently interpreted as seminal for the theory of democracy that the American political-science debate developed (Piano 2019). Second, and more important for this paper, are the arguments that Pareto and Mosca used to criticise (for instance, universal suffrage) based more on anthropological and psychological assumptions that, for them, characterise human nature, than on the belief in laws concerning the actual development of society.

This latter consideration introduces the main argument of this paper, which contends that the elitists' notion of social laws basically reflects their ontological assumption and does not necessarily influence the epistemological dimension of their thought. Such a distinction, though recent in the academic debate, is crucial to assess elitist epistemology relative to the standards of the time and how it later evolved.

According to the contemporary debate, ontology reflects scholarly beliefs about the very nature of the world. In this sense, Marsh and Furlong (2002) have distinguished two classes of ontology in the social sciences: foundationalist and anti-foundationalist. Scholars adhering to the former accept the existence of a real world, independent of the observer, while those adopting the latter very often tend to deny or undermine such a condition. Conversely, epistemology pertains to the conditions under which knowledge is possible. While anti-foundationalist ontologies imply a hermeneutical epistemology that refutes causation in principle, foundationalism is compatible with different epistemological stances that can be conflated into two broad categories: 'positivism' and 'realism'. Both approaches assume that social structures exist and are causally linked to outcomes, but they diverge on crucial aspects. First, the belief that social laws do exist and are directly observable characterises positivism (ivi: 20 and passim). Also, positivists generally do not believe in any sort of reflexivity of the social sciences, meaning that human understanding of reality (e.g. values, beliefs) has no impact on outcomes. These two features constitute the essence of realist critiques of positivism. Hence, this perspective supposes social structures to have causal power, albeit not immediately observable. Moreover, reflexivity is accepted; at least to some extent, agents can change the structures in which they find themselves (Bhaskar 2008; Archer 1995) in light of their beliefs.

The establishment of a post-positivistic epistemology found momentum with Robert K. Merton's critique of functionalism. The sociologist is also known for the notion of middle-range theories, understood as an attempt to recast the scope of valid generalisations in the social sciences (Merton 1949). In the same vein, several authors in the second half of the twentieth century built on this idea to propose contextualised explanations as the feasible standard. Published in 1975, Roy Bhaskar's 'A Realist Theory of Science' systematised a critique of positivism and gave birth to contemporary epistemological realism. The work is seminal for the development of epistemology in the social sciences, contributing to critically revising the idea of social laws as empirical reality, despite urging reflection on contextual features, mechanisms and agency.

In line with this perspective, Jon Elster-one of the most prominent social theorists-repeatedly advocates for the search for mechanism-based explanations to replace functionalist fallacies $(1989 ; 1960)$. In particular, Elster stresses the importance of understanding the nature of agents and their motives. Despite his view of the social sciences as a reductionist process, he denies any form of determinism. As a matter of fact, Elster advocates for mechanisms instead of laws because they can account for social outcomes in multiple ways (1960), meaning that the way they link to actual outcomes is neither linear nor simple.

The same critical reaction to positivist epistemology is also vibrant among public-policy scholars and, more precisely, among programme-evaluation specialists. In particular, Ray Pawson (2013) (Pawson and Tilley 1997) champions an attitude towards causality assessment that focuses on the notion of 'contexts' and 'mechanisms' as the only two elements of a social system that, interacting with a policy intervention, can have causal power. Here, the adoption of a realist perspective is endorsed to fully account for social 
outcomes that are causally linked to intentional human (and more specifically governmental) interventions and, thus, difficult to frame within a purely positivistic perspective. ${ }^{1}$

Authors sharing a realist epistemology usually agree on these features of mechanism-based explanations that distinguish them from law-like explanations:

1. Mechanisms are agent-based. Social phenomena are primarily the product of the mechanisms rooted in the psychological stances and emotions of individuals. In turn, social mechanisms underpin the aggregation of behaviours. In other words, even an explanation of the most complex social phenomena should ideally refer to some microfoundations.

2. Mechanisms are context-dependent. Depending upon situational features, a mechanism can or cannot activate. If it operates, a mechanism can bring about different outcomes; at the same time, due to contextual features, different mechanisms can lead to a similar outcome. This means that multi-finality and equifinality affect social phenomena.

3. Mechanisms are not self-evident. Since mechanisms are about agents' motives and preferences, they are often 'hidden' (Pawson and Tilley 1997: 65) under the surface of social phenomena. For this reason, Elster claims that any social explanation should 'at least suggest[ed]' (1989: 4) mechanisms because most of the time they remain inaccessible and can only be grasped through proxies.

In the following sections, I argue that these three features of realist epistemology were also incubated in many of the elitists' causal interpretations of social phenomena. The reasons that elitists thinkers are commonly associated with positivism relate to the ontological dimension of their thought. Hence, the cornerstones of Pareto and Mosca's social theory - the belief in the invariability of some basic human features, such as the cleavage of rulers and ruledrelate more to the ontological core of their thought and, in principle, can be compatible with both a positivist and a realist epistemology. Although Pareto and Mosca profess faith in the possibility of scientific knowledge through discovering regularities in the social domain, their notion of social law often resembles the definitions of social mechanisms developed later in the post-positivistic debate, namely, explanations whose validity is contingent on specific configurations of contextual elements.

\footnotetext{
${ }^{1}$ As will be explained more fully in the rest of the paper, such a debate deserves attention because Vilfredo Pareto has been considered one of the founding fathers of policy analysis (Samuels 1974).
}

\section{3 'Realist' Elements in Elitists' Epistemology}

In one of his writings about the two most prominent elitists, Norberto Bobbio writes: 'Gaetano Mosca has been a positivist throughout all his life, until the illusion; Pareto, at the onset of his scientific career, was mostly an upset idealist' (2001: xiii, my translation). Yet, this sharp conclusion only refers to beliefs in the policy relevance of social knowledge-strong in Mosca and weak in Pareto-and not to the authors' epistemological stance. In fact, Pareto also considered himself a positivist. He explicitly describes his works as the attempt to translate the scientific logic of physics, chemistry or biology into social matters (Bobbio 2001: 37-38; Mornati 2006: 581). The works of Comte, Darwin and Spencer influenced both Mosca and Pareto, authors whom the elitists would eventually criticise for proposing overly simplistic interpretations of social phenomena. ${ }^{2}$

In what follows, I argue that despite elitists accepting some of the scientific premises of mainstream positivism, they also developed an original and - in many respects-dissonant framework for the analysis of society. In particular, I focus on three aspects that underpin my argument. First, elitists did not truly believe that social laws are immediately observable; yet, they are grounded on assumptions about the hidden psychological inclinations of men. Second, the regularities that describe, explain and (hopefully) could predict the aggregation of individual behaviours and, thus, account for social outcomes are far from simple and linear. Both Mosca and Pareto are more likely to describe the evolution of social phenomena through time in terms of cycles rather than lines, reflecting this point. To account for this, we discuss Mosca's denial of Darwinism to explain political development and Pareto's critique of the Historical School of Economics. The third and final element relates to the role of intentionality in explaining social phenomena. In this respect, Pareto's critique of determinism was crucial for the development of scholarly consideration of policy.

\footnotetext{
${ }^{2}$ In the case of Pareto, the other major source of influence was the notion of 'equilibrium', developed by Warlas, and which Pareto himself refined significantly in the field of economics (Mornati 2018) and eventually tried to extend in the field of sociology. The whole social system, in Pareto's understanding, should have been conceived as a more complex system, where the equations leading to the equilibrium in the economic domain interact with those determining the equilibrium in the domains of power and beliefs (Powers and Hanneman 1983). Besides, Bouvier (2012) gave a convincing illustration of John Stuart Mill's influence on Pareto.
} 


\subsection{Digging Out Hidden and Agent-Based Mechanisms}

Despite his positivistic pedigree, Pareto progressively developed a theory of society at odds with any positivist thinkers of the time. More specifically, his refutation of mainstream sociology is grounded on a more general rejection of an organicistic notion of society. Yet, he was developing an analytical sociological perspective, aimed at dissecting the basic elements of social life.

What contemporary social sciences call methodological individualism represents one of the building blocks of his sociology. Pareto considers 'individuals' as the 'molecules' of the social system (Pareto 1964: §2080). Only agents exist, and social facts, though complex, compose their attitudes, behaviours and interactions (ivi: $\S \S 118,119)$. The microfoundations of Pareto's sociology are his notion of 'residues', deeply rooted instinctual attitudes that account for each agent's inclination towards stability or change in the system in which he/she lives (ivi: §870).

Long before the Treatise, Pareto's economic thought reflected the necessity of grasping the psychological foundations of human behaviour, to replace a purely deductive notion of utility (see: Pareto 1906: 35). At the same time, Gaetano Mosca, acknowledging economics as a more advanced discipline than political science, recognised that it would probably have benefitted from a better understanding of human psychology (Mosca 1953: 10, 61-63). ${ }^{3}$

Pareto's obsessive attention to individuals' motives and emotional drivers had great success in the USA, where psychological studies anticipated and, to some extent, conditioned the development of sociology and political science. Thanks to the enthusiastic reception by Talcott Parsons (Dalziel and Higgins 2006), who, in 1935, edited the American version of the Treatise, Pareto became a source of inspiration for scholars of different disciplines. Conversely, it was not unanimously welcomed in Europe. For instance, Raymond Aron (1937) strongly criticised Pareto's sociological thought exactly for its 'psychologisme' and 'dogmatisme', namely, that individual instinct and attitudes are only superficially invoked (which is true) and mechanically applied for the explanation of social facts.

The fallacy of this critique, I believe, lies in the confusion between the ontological and the epistemological dimensions of elitists' thought. The taxonomy of residues (understood as fixed mechanisms of human action) only reveals a foundationalist ontology but does not necessarily

\footnotetext{
${ }^{3}$ Such a research agenda was clearly in tune with the cognitive turn in social sciences that Friedrich von Hayek was developing in the same years, and Herbert Simon would later deploy (see Marchionatti and Mornati 2020).
}

imply a deterministic epistemology. In fact, psychological reductionism does not make Pareto insensible to complexity. Although highly stable forces that residues represent mainly drive individuals, interests and beliefs also influence actual behaviours. The latter, which Pareto calls 'derivations', are an extremely volatile element of the social system, and contrary to the Marxist notion of ideology, they are not only determined by residues and interests but can occasionally have causal power.

Eventually, Aron came to a more balanced assessment of Pareto's sociology and acknowledged his originality. ${ }^{4}$ In particular, he noted that the critical remarks Pareto moved to nineteenth-century scientism largely depended on his theory of action, since 'there is no scientific solution to the problem of action' (Aron 1970: ch. 5, §1). Somewhat ironically, this aspect of Pareto's thought seems to have anticipated some of the ideas of Jon Elster (see: Bouvier 2012), probably the most important among Aron's students. Elster conceives of social science as a process of reduction to psychological variables (Elster 1989: 74), in which sentiments and emotions play a great role. Also, individuals' attitude towards adjusting preferences and ideas in light of interests and feasible opportunities (Elster 1983) likely constitutes the most distinguished feature in Pareto's sociology, to the point that some scholars argue that his notion of 'derivations' - rationalisations of the reality serving a variety of human needs and goals - makes him the father of the sociology of knowledge (Berger 1967) and ideologies (Bobbio 2001).

\subsection{The 'Cycle' Instead of the 'Line': Elitists and Temporality in Social Research}

Both Pareto and Mosca had been influenced by the evolutionist theories of Spencer and Darwin. Although they acknowledged that these lenses overall contributed to the advancement of the understanding of social dynamics, they also refused the deterministic assumptions they ushered in the debate. In this respect, a striking difference between elitists and the positivist mainstream is the prevalence of the cycle over the line. Metaphors can be sound indicators of the deep structures underpinning frameworks and theories developed by social scientists, and thus, they can reveal scholars' ontological and epistemological beliefs.

In this sense, elitists tend to reject the idea of progress and strongly criticise the idea of linearity as an oversimplifying assumption concerning the development of human affairs. The very idea of 'elites circulation', common to both

\footnotetext{
${ }^{4}$ In his Main Currents in Sociological Thought, Aron explicitly admitted that his harsh 1937 assessment of the Treatise was influenced by the political conflict in Europe and, in his final remarks, excluded Pareto's sociology as, in any respect, an apology for fascist ideas.
} 
thinkers, perfectly fits this metaphor. Nonetheless, the cyclical structure of their thought not only relates to the ontological dimension; it also affects the epistemological dimension and has to do with the best approach to addressing temporality in social research. Both Mosca and Pareto often advance patterns of causation in which, over time, causes can become effects. An example is a given policy that becomes driven by ideology more than interests (Pareto 1964: §1732); another is a cause accounting for the success of a business or a political venture at a given point in time which, in the long run, paves the way to the ruin of the same undertaking.

In this respect, elitists finding a major source of inspiration in modern age thinkers, such as Montaigne, Bayle and Machiavelli, seems significant (cfr. Bobbio 2001: passim; Berger 1967: 267). However, the influence of these authors concerns not only elitists' erudition or their polemic vis but also their epistemology. For instance, whereas it is accepted that Machiavelli's The Prince deeply shaped how Pareto developed analytical categories about elite circulation, the influence of early-modern thinkers on his epistemological stance has probably been overlooked. For example, The Prince's argumentation style by 'norms and exceptions' (Ginzburg 2003)—grounded in medieval casuistry, as are other classics of renaissance thought (Ginzburg and Biasiori 2018)—recalls elitists' caution about linear generalisations. Beyond Machiavelli, Torquato Accetto's Della dissumulazione onesta, published in 1641, is likely to have been another source of inspiration for Pareto. Bouvier notes that his theory of derivation is used massively to shed light on the phenomenon of 'dissimulation' as a strategy for persuasion (Bouvier 2012: 136-7).

Although Mosca and Pareto considered the knowledge of history essential, the two authors diverged on how to use it. While the author of the Elementi, due to a humanistic background, is always loyal to the 'historical method' (Mosca 1953: 64), Pareto always advocates for the deductive approach supported by proper formalisation. Faithful to the same analytical approach, he ventures into the field of sociology, motivated by the aim of making sense of complexity.

\subsubsection{Mosca on Political Development}

For Mosca, one reason political science remained underdeveloped relates to the intrinsic complexity of the subject matter (Mosca 1953: 15). For this reason, he strongly criticised theories providing an oversimplified account of social phenomena and their evolution in time. From this perspective, the first chapter of the Elementi-dedicated to methodological issues-directly questions the linearity of social and political change, mostly based on physical and biological variables. For instance, he contests the geographic and climatic determinism of Paul Mougeolle (see also Tarde
1886) and racist theories, such as those that Ernest Renan and Joseph-Arthur De Gobineau elaborated.

Mosca aims not at confuting evolutionism per se but arguing that it simply does not apply to human affairs. If simplistic theories were accurate, Mosca argues, social change would occur gradually, and major political change and even revolutions should never take place; those in power-having more skills and resources-would be expected to simply transfer their dominance to their heirs, but history clearly shows the contrary (Mosca 1953: 101).

Conversely, Mosca advances the idea of a ruling class as an alternative 'law' that, better than physical and biological factors, can explain political development in time. This said, Mosca arguably was simply replacing a brand of reductionism with a different one based on political factors. As the previous section states, to consider the ruling class a general law of development is difficult; it is more a constant feature of human societies. Hence, it cannot be used to predict specific outcomes, insofar as it cannot be transposed to an 'if X, then Y' proposition. The only thing it predicts is that despite all the possible political changes that may occur, a minority will rule over the majority - quite a tautology. Yet, Mosca shows great interest in analysing and puzzling over variations occurring across time and countries.

For instance, bureaucratisation is a topic in the area of political development in which Mosca's peculiar view concerning historical causality did emerge, comparable to the suggestion of other prominent thinkers who lived between the nineteenth and twentieth centuries. Max Weber was a benchmark. The iron cage metaphor, with its strong teleological assumptions of the inevitability of rationalisation processes, had a legacy effect on academic thinking, up to Joseph Schumpeter's (failed) prophecy of the superiority of socialism.

In this respect, Mosca and the elitists generally had a more nuanced view. A recent work by Dochron (2020) shows significant differences between Robert Michels and Max Weber on the organisational development of political parties. Hence, contrary to the traditional interpretation of his works, Michels's imagined possible limits to oligarchic tendencies in organisations and society appear in intra- and inter-party competition. For its mentor, only exogenous factors, such as the rise of charismatic leadership, could have tamed them (Drochon 2020: 8).

For Mosca, the rise of bureaucracy has a cyclical and punctuated development. First, Mosca distinguishes between the 'feudal State' and the 'bureaucratic State' (Mosca 1953: 123 ) and admits that the bureaucratisation of certain aspects of society is a condition for the success of a given polity. Yet, such an evolution is not a linear function of a broader evolution from a simpler to an increasingly complex organisation. He also argues that when bureaucracy spills over into new social domains and trespasses on certain levels, it 
will foster decadence and eventually pave the way for a debureaucratisation: 'This is one among the many clues about the great complexity of social laws, whereby a political order producing good results when applied under certain limits, it becomes unfeasible and detrimental if systematised and generalised' (ivi: 131). More specifically, reflecting liberal ideas of economy, Mosca criticises State intervention in economic affairs and, contrary to Schumpeter, contemplates the possibility that increasing regulation might bring about entropic tendencies.

\subsubsection{Extrapolation and Interdependence in Pareto}

Pareto's denial of linearity depends on both his ontological and epistemological beliefs. Among the former, his belief in the relevance of non-rational drivers to social outcomes certainly plays a role, and scholars consider it an original feature of his thought. Yet, his epistemological assumptions have been less analysed. I contend that his micro-analytic approach, specifically to the notions of 'residues' and 'derivations', is crucial to understanding Pareto's critique of determinism. Hence, for Pareto, social facts cannot be studied as simple elements because they appear to the social scientist as complex and stratified. The recurrent analogy here is with the composition of minerals. Like the composition of rocks, 'residues' and 'derivations' interweave through social facts in complex and always different combinations (Pareto 1964: §2080). ${ }^{5}$ Since social facts are intrinsically complex, the laws underpinning their evolution must be the same.

Already in the Cours, Pareto singles out the fallacy of extrapolation-the assumption that a certain observed development will assume the same direction and pace in the future-as the main problem of the historical school of economics, whose scholars over-stretched the Darwinian notion of adaptation to justify every existing institution as the most efficient (Pareto 2005: §578, §625). ${ }^{6}$

Yet, the fact that formal models cannot account for real events should not be considered a problem per se. Since science operates through a reductive process, it oversimplifies some intrinsically complex aspects of reality. In turn, such a

\footnotetext{
5 This consideration also ushers in methodological considerations. Despite residues constituting the most potent drivers of social actions, Pareto thought they are almost impossible to detect empirically, and the only way to bring them into the analysis is by dissecting their by-products, such as interests and derivations (Pareto 1964: §886, \$2083).

${ }^{6}$ Interestingly, Pareto always refers to the School and never mentions the authors who composed it. Notably, Gustav Schmoller is absent both in the Course and the Manuale, while he is mentioned one time in the Treatise as an example of how economic theories are often developed to serve national policies (Pareto 1964: \$2211). The arguments Pareto uses to criticise historical explanations are strikingly similar to those Karl Popper uses in his The Poverty of Historicism.
}

mismatch fuels impressions that theories should be amended to account for the many 'exceptions' left unexplained (Pareto 1964: §101). For Pareto, this is a capital mistake; an interdisciplinary approach combining theoretical tools taken from several sciences should be adopted as a mindset and a practice to cope with complexity (ivi: §2022). To do that, he brought along the notion of equilibrium from economics, as the social system is supposed to evolve out of the mobilisation and countermobilisation of opposing forces underpinning the economy, power and belief domains of societies. Nonetheless, more than equilibrium, interdependence is probably the most important conceptual lens through which Pareto builds his Treatise (Marchionatti and Mornati 2020).

While it is not disputable that Pareto tried to develop a general equilibrium model for the whole society (Samuels 1974; Powers and Hanneman 1983), pursuing such an intention in many chapters and sections of the Treatise, some sections and arguments seem dissonant with this picture. Pareto extremely convincingly shows how social phenomena are interdependent, but his attempt to build a generalequilibrium model was probably too ambitious. Long before the Trattato was struck, Pareto had no confidence that a mathematic formalisation would fit the nature of sociology, not least because many variables cannot (and never will) be measured (Pareto 2005: §584, §610; Pareto 1964: §2062ff; see: Mornati 2018). However, the determination of social orders is a question not only of dealing with a more complex system of equations (see Powers and Hanneman 1983) but of a different underlying logic. In Pareto's reasoning, social equilibria appear as the result of combinatory processes in which the building blocks of his sociology can assume different configurations and lead to unpredictable outcomes.

Pareto's epistemology was quite advanced for the time in which he lived. He always acknowledges that science has limits and experimental truths are conditional (1964: $\S 540, \S 973)$. As social facts are considered, more limitations and conditions should be considered, not because 'laws' are not operating but simply because many 'laws' of different natures operate at the same time (ivi: §101). This led Pareto to look at causation as a complex pattern of non-homogeneous drivers. Despite the allegation of 'dogmatisme' that Aron initially raised for the mechanistic conception of human actions, Pareto conceives of the 'residues' as 'indeterminate' concerning their outcome. In other words, he thought that whether they are capable of having causal power (i.e. making something happen in society) is not predictable, nor is the direction of causality (T: $§ 874)$. This means that the impact of a 'law' is context-dependent, implying that social phenomena are highly subject to multifinality and equifinality. 


\subsection{The Place of Intentionality: Pareto and the Birth of Policy Sciences}

Among the classics of the social sciences, Pareto was the first to identify the domain of public policy (Samuelson 1974). Even in this respect, his epistemological stance is crucial. The importance of policy as a goal-oriented human intervention derives from the analytical distinction between 'real' and 'virtual' movements, notions that Pareto borrowed from mechanics (Pareto 1964: $\S \S 129,130$ ). 'Real movements' belong to what effectively happens in a given system, while 'virtual' applies to phenomena that have not yet taken place. If determinism is right, virtual movements would have no importance, though Pareto neatly refutes such a position as a fallacy. Whereas some virtual movements encompass impossible events, phenomena that had not actually taken place could be (or could have been) real. The understanding of such 'movements' is vitally important for the social sciences.

Among virtual movements, public policies constitute important ones. In this respect, Pareto not only understood that purposive behaviour does affect the social structure; he also de-rationalised such a process. First, the assumptions by which a legislator operates on reality is often far from perfectly rational, as he or she likely suffers from insufficient information or is even driven by prejudices. Pareto offers many examples to show how the most prominent statesmen sometimes ignore crucial, albeit insignificant contextual aspects that eventually jeopardise sound, evidence-based policies. Such an argument applies to many subjects but is often used to polemise against economists, both liberal and protectionist, who advocate for the policy relevance of their models. Yet, Pareto argues that neither pure economics nor an applied economy can fully account for a policy success or failure (Pareto 1964: §2014, §2016).

In this sense, Pareto significantly contributes to developing policy studies, filling the gap between deductive models and their application to reality. In theoretical terms, Pareto acknowledges not only that attitudes, interests and beliefs influence concrete outcomes but also, the specific way in which these simple elements are distributed among the individuals operating in concrete systems of action-what he calls 'social heterogeneity and circulation'-essential to understanding social phenomena (ivi: §\$2204-2207, $\S 2207 \mathrm{ff}$ ). As this paper argues later (§5), Pareto was fully aware that policy outcomes are context-specific and, thus, convergence models may not emerge.

Second, even assuming a rational decisional process, policies usually produce unintended consequences that often are far more remarkable and durable than the intended ones. Partially confuting in the Manuale and the Treatise some conclusions reached in the Cours, Pareto admits, at least hypothetically, that protectionist policies could bring about non-economic effects that nonetheless are worth a loss of economic wealth that the policy produces.

A related third feature characterising Pareto's conception of public policy is the indeterminacy of evaluation criteria, which may vary according to the stakeholder and the deliberation process leading to a given policy design. ${ }^{7}$ Hence, Pareto was one of the first thinkers to question the commensurability of the notion of utility. In fact, public policy has little room for 'logical-experimental theories' because goals are 'not determined, or, if they are, they are not self-evident' (Pareto 1964: \$2146, my translation). Such a condition is not entirely (nor even mostly) dependent on the fact that sentiments drive people more than reason. Instead, since they involve power relations, public policies are normally evaluated using criteria that may be justifications of hidden agendas. Moreover, unlike Marxism, such ideational elements may have a causal role, in that the actors can use them to persuade and manipulate others. However, such a critical perspective on the nature of public policy should not be interpreted as 'irrationalism'. ${ }^{8}$ On the contrary, if on one side Pareto emphasises the existence of a subjective and nonrational dimension of the society, on the other he admits that certain policies can be 'objectively' useful for both single individuals and larger groups up to the national community.

\section{Mosca and the Critique of 'Nations' and 'Races' as Explanatory Variables}

Social sciences in the age of positivism largely embraced social Darwinism, the extension of biological characteristics of specific groups (Rogers 1972). A racially based interpretation of society had been a central theme since the eighteenth century (Sebastiani 2013), and not until the midtwentieth century had theories of social development been progressively 'de-biologicised' (Mazrui 1968) and rejected in the contemporary debate.

Various strands of literature highlight how the belief in superior and inferior races might have fitted the ontological premises of scholars who more or less intentionally rationalised their countries' dominance over new areas of the world (Popkin 1973; Hunter 2002; Jeynes 2011). Howeever, racebased interpretation of social phenomena was also in tune with the epistemological stances of modern-age mainstream social sciences, particularly those of positivism. In fact, biological arguments perfectly fitted the need for simple and

\footnotetext{
${ }^{7}$ For a contemporary perspective on these issues, see Pawson and Tilley (1997) and Majone (1989).

${ }^{8}$ On this very point, Raymond Aron admittedly changed his assessment, as in Main Currents of Sociological Thought, where he correctly disentangled Pareto's non-logical actions from irrationalism.
} 
strong correlations between social phenomena, such as different stages of social and political development or patterns of deviant behaviours.

Thus did arguments fitting the scientific standards of their times, about the impact of race-based interpretations of society, surround elitists. Decades before the advent of fascism, the Italian scientific debate on the first colonial enterprises took for granted biologically grounded arguments used to justify the country's colonial policy (Bonmassar 2019). Despite such debate, elitists were quite far from embodying these arguments in their theories of politics and society. Neither Mosca nor Pareto directly confute the very existence of races (Mosca 1953: pp. 46-47; Pareto 1964: §2065), but both had resolutely excluded such factors from having a relevant impact on socio-political phenomena. ${ }^{9}$ Rather, elitists discard racial arguments as conceptually ill-defined, oversimplistic and ideological.

As stated, the methodological chapter of Mosca structures the Elementi di Scienza Politica as a reply to physical and racial determinism (1953: 16). First, the author questions the semantic ambiguity of the notion of race and how physical characteristics, such as skin colour, can induce fallacies if assumed to be indicators of different races. According to Mosca, human groups are constantly reshuffled one in another (ivi: 35), and thus, the explanatory power of races had to be undermined and confined.

As a rigorous analyst of ideologies, Mosca could not avoid detecting how social Darwinism, as a scientific movement, also expressed colonial powers. This creates the opportunity for two intimately related kinds of fallacy. The first is ex-post justification. Certain races are considered superior just because they won over others, and this kind of reasoning constructs rankings among them. However, Mosca argues that 'given that things went in a certain direction does not imply they necessarily had to go that way' (ivi: $38, m y$ translation). Different stages of civilisations were reached (or not) for reasons that had nothing to do with biological characteristics, and chance played a major role in explaining the domination of one group over others. Moreover, Mosca acknowledges that the development of a civilisation often occurs by abrupt leaps, while biological explanation would have been consistent only with a gradual process of evolution. The fact is that political development is not a 'struggle for existence' but a 'struggle for domination [preminenza]'

\footnotetext{
9 This seems mostly true for Gaetano Mosca. Vilfredo Pareto analyzes the dynamics of the social system by gathering historical evidence from European and Middle-East societies, to avoid raising 'severe and unsolved' issues. In explicating such a caveat, Pareto is not arguing that races exist, just trying to stick to scientific standards and isolate variables that could have invalidated the robustness of the model (T: §2065)
}

(ivi: 47). ${ }^{10}$ Such a process, despite few exceptions, does not eliminate losers but includes them in the societies that conquering powers rule. In the same manner, Pareto strongly undermines racist interpretations of divergences in national wealth. Some ethnic groups (says the Cours) are wealthier than others because colonisers have been lucky enough or smart enough to occupy and colonise the most productive territories first (Pareto 2005: §605).

This argument is strictly connected with the critique of 'race' as an ideological tool that dominant powers play to justify their rule. Pareto neatly classifies racial arguments as 'derivations' (Pareto 1964: §1050-1051); he did not indulge in examples of the role of this ideology in the social system. Conversely, Mosca gave a brilliant illustration of how ideological beliefs can produce real effects at the micro-level. For example, he criticises the Polish sociologist Ludwig Gumplowicz-who probably elaborates the most sophisticated among the 'racist' theories of that time-for thinking that races somewhat determine social classes. 'Against this assertion', Mosca argues, 'several facts can be reported and, among these, the obvious one represented by the fact that members of the same family quite often belong to different classes' (Mosca 1953: 100ff, my translation).

Moreover, the author uses some evidence concerning the divergent educational performances of white and coloured people in the USA, reported by Henry George's Progress and Poverty, to argue that taken individually, all persons have more or less the same capabilities, but 'once [blacks] started to understand they will occupy lower places in society, they become less motivated and apathetic' (Mosca 1953: 41). In other words, for Mosca, differences in the distribution of power depend on the distribution of resources, which the virtue of prestige then reinforces. In any case, the phenomenon depends on social and political factors affecting interindividual relations, not biological predetermined drivers. Second, and most relevant for the sake of this paper, biological explanations are erroneous because simple and linear, whereas the underlying phenomenon is a matter of historical configurations, agency and even chance.

These examples show that elitists were significantly in tension with the positivist mainstream on the issue of race, mainly for epistemological reasons, whereas the conservative attitudes of the same authors, which Hirschman assumes are a strong bias underpinning their belief in social laws, would have perfectly fitted such a zeitgeist.

\footnotetext{
10 This argument is probably influenced by Ludwig Gumplowicz's theory of social conflict contained in his Rassenkampf. Though the study is quoted in the Elementi, Mosca does not mention it at that point.
} 


\section{The Problem of Economic Development: Pareto As an Ante-Litteram Political Economist}

Contemporary political economy widely accepts the impact of social and political variables, and scholars successfully detect it. In particular, including in models the idea that 'political cycles' do affect macro-economic policies is only relatively recent (Alesina 1989). The same applies to understanding successful industrial policies, linked to subtle factors related to the nature of economic, political and administrative actors; for this reason, they hardly fit formal models (Schumpeter 1944; Hirschman 1958; Evans 1995; Breznitz and Ornston 2018).

All these themes are highly developed in Pareto's thinking and particularly vivid in his controversies against freetrade economists on the one side and, on the other, the rising advocates of infant industry, via such protectionists as the followers of the Germans Friedrich List and Gustav Schmoller. Both sides, Pareto argues, went far beyond the mere exercise of scientific knowledge in the field of economics. Instead, they developed or just stretched particular theories, to serve personal gratification and policy-makers' convenience (Pareto 1906: pp. 414-5; Pareto 1964: §2016, $\S 2211)$.

Yet, Pareto's critical vis is not only devoted to deconstructing the ideological nature of economic theories, no different from what Marx had already done. Rather, it also focuses on the indeterminacy of economic variables alone as predictors of policy-intervention outcomes. The success of economic policy does not depend only (nor mostly!) on the degree to which strategies and measures are consistent with sound economic theories. This is one of his most original ideas (Samuels 1974), and I argue that epistemological assumptions that he developed as a structure for his entire social theory constitute the cornerstone upon which this belief could have developed.

After his works on economic theory, Pareto rejects simplistic causal assumptions and, building on Bastiat, develops the idea that economic phenomena are internally and externally interdependent, meaning that each economic variable affects and is affected by other economic variables, as well as non-economic ones (Pareto 2005: §601-2). Then, he critically notes how most economists 'are hardly capable to conceive that social relations are not simply cause-effect; they only want to uncover the cause of value, the cause of migratory phenomena, etc.' (ivi: §594, my translation, italics in the original). Such an epistemological stance refuses both 'fatalism' and 'determinism' (ivi: $\S 606)$ and raises a strong policy implication, according to which governmental intervention is neither sufficient nor necessary for the prosperity of a given country but can nonetheless be an important factor of social change among the others (ivi: §605; Pareto 1964: §§1863-5, §2096ff).

The same line of reasoning sketched in the Course in the late nineteenth century would be further developed two decades later, in the Treatise. In this period, Pareto's thinking on economic policy underwent a significant change. In fact, if the Cours did not question the superiority of free-trade over protectionism, Pareto immediately noted in the Manuale, written exactly in between the other two works, that economic policy cannot be judged theoretically but only evaluated ex post. More importantly, he acknowledged that in such an assessment, not only economic values but also other kinds of values can be (and usually are) considered (Pareto 1906: viii-ix).

Significantly, Pareto uses the debate on protectionism and examples from European experiences of industrial policies in the section of the Treatise called 'Cycles of interdependence' (Pareto 1964: Ch. XII, §§2203-2236). Paragraph $\$ 2018$ particularly condenses the essence of Pareto's notion of interdependence between political and business cycles. Here, the author illustrates how and why pure economic theories of any kind would eventually fail to explain divergent growth models that specific countries undertake and their different probabilities of success.

To do that, he sketched two paired comparisons of the United Kingdom and Germany, on one side, and Germany and Italy on the other. This case selection allows the author to highlight how both equifinality and multi-finality affect the same policy problem, depending on the timing of taking protection measures and the nature of both political and business actors in any given polity. In fact, the United Kingdom and Germany provide a striking example of how two opposite policy strategies-free trade and protectionism, respectively - can produce the same outcome, namely, industrial development. Conversely, the comparison between Germany and Italy supports the argument that the same industrial strategy - the Italian establishment starting in the late nineteenth century to borrow policy recipes from Germany-does not necessarily produce the same outcome.

In particular, Pareto aims at demonstrating that Germany was an experiment that could hardly have been replicated. The success of this development model relies on the fact that an extraordinary conservative ethos (in Pareto's terms: II class residues) characterises the political elites undertaking protectionism and direct industrial policies, which conveniently countervail the innovative forces coming from the business domain. This outcome could happen only because in Germany, protection in agriculture and industry functioned in parallel, so the former preserved and reinforced the status of territorial aristocracy, which constituted the backbone of the political elites (see also Pareto 1906: p. 478). Such a configuration, Pareto argues (a recurrent theme in the Treatise), is exceptional. When a polity engages with development processes, it will very likely transfer a 'combinations instinct' 
from societal actors to the ruling elites, by mechanisms of imitation or co-optation. In turn, such a change in the attitudes characterising the agents exerting public authority functions normally brings about collusive relations between the political and the business domains, which then bring about extractive economic policies.

In this respect, Italy represents for Pareto the most suitable example for demonstrating the reasons not to imitate Germany's development model. Such reflections emerge long before the Treatise, as Pareto had always assumed critical stances in the public debate when, in the late nineteenth century, Italy undertook a comprehensive alliance with Germany, endorsing both militarism and industrialism. He addresses critiques to both the political and the economic elite, allegedly driven by strong collusive instincts. For instance, in his letters to Liberty - a Boston-based anarchic journal-Pareto describes how the ruling class used the rhetoric of industrialism - mimicking the German model-to justify pork-barrel policies aimed at fostering local patronage and industrial speculation (Pareto 2018). Almost two decades later, in the Treatise, the assessment of German and Italian development is quite consistent. The Italian way to protectionism could not rest on an efficient bureaucracy, which in Germany, the co-optation of territorial gentry in the administration and the army grant. Thus, a similar economic policy would have different outcomes because of noneconomic variables (Pareto 1964: $\S \S 2218 \mathrm{ff}, 2219)$.

However, in this exercise in comparative political economy, no single instance of social equilibrium emerges from Pareto's work. In fact, the intersection of the political and the business cycles can be evaluated in light of two outcomes. The first refers to economic development, and the other is about the military projection of the state. Whatever equilibrium a polity reaches, Pareto stresses how it can be suboptimal, with plenty of negative and potentially disruptive side-effects. One pattern occurs in polities in which economic development corrupts the ruling elite. On the economic side, intrusive policies are likely to be inefficient; speculators would eventually extract resources from those groups in the society with no political voice. Conversely, in political terms, the rise of business actors and their capacity to influence and penetrate the ruling class has a 'positive' impact on militarism, lowering the propensity of government to engage the country in warfare (Pareto 1964: §2178). Instead, in his reflections on Germany, Pareto seems to draw on a completely different state of equilibrium, in which the stability of conservative instinct in the ruling class allows the protectionist policy to succeed, but (and this is the downside) in the long run, it fuels militarism. Hence, both the attitudes of the aristocratic ruling class and the interests of the industrial corporations that flourished, thanks to protectionism, underpin the power politics of the State (ivi: §2218, §2224, §2256).

\section{Conclusion}

Mosca and Pareto lived in an era in which positivism constituted the mainstream academic discourse, and they contributed to such an intellectual movement. In this paper, I try to argue that, from an epistemological point of view, elitists were in tension with positivism as they raised critical remarks on important assumptions that were dominant in the social sciences of their times.

Moreover, the paper shows how the two authors anticipate important features that constitute building blocks of the realist epistemology in contemporary social science. In particular, this paper confirms Bouvier's interpretation of Pareto (Bouvier 2012) and extends its validity to Gaetano Mosca. Hence, both elitists, despite different backgrounds, mainly focus on agents and their hidden motives. Besides, the articulated nexus between action and beliefs anticipates both the cognitive turn in the social sciences and the emergence of public policy as a distinctive domain of knowledge. Yet, the importance of beliefs formation does not limit elitists' ante litteram epistemological realism. Building on microfoundations, elitists conceived the regularities-'laws' - underpinning social and political dynamics in a way that impressively resembles the debate on social mechanisms. In their view, social dynamics do not fit simple linear models. Phenomena with a strong temporal dimension do have causal implications that rely on the combination and sequencing of more elements, which, per se, can affect social outcomes in a great variety of ways. The examination of the debates on a racist theory of history and national economic policy illustrate these features. In both cases, Mosca's and Pareto's contributions seem to support the hypothesis this paper advances.

Such a conclusion directly leads to a tricky question that cannot be ignored. Why-except for Bouvier's assessmenthas such an advance that elitists reached on the epistemological frontier of the social sciences not been fully uncovered so far?

I have no straightforward answer to such a question, and certainly, any inaccuracy in some of the most prominent thinkers in contemporary social science should be excluded. ${ }^{11}$ Arguably, if a classic such as Pareto has been overlooked in many respects as a seminal contributor to social theory and public policy, it is because of his association with an obsolete epistemology. Neglecting positivism, many social scientists have probably missed the occasion

\footnotetext{
11 It is curious in this sense that Pareto is not mentioned in Elster's Sour Grapes (1983) and, to my knowledge, also in his other works. Even more paradoxical is the fact that Pareto's legacy is completely missed in Ray Pawson's Realist Manifesto (2013), whereas the author includes Elster among the 'precursors'. The same goes for Alesina's work on the interactions between business and political cycles, and the list can be expanded further.
} 
to engage with some vital ideas that elitists develop, which have found a stable place in the social-science debate only in the second half of the twentieth century.

Funding Open access funding provided by Università degli Studi di Genova within the CRUI-CARE Agreement.

Open Access This article is licensed under a Creative Commons Attribution 4.0 International License, which permits use, sharing, adaptation, distribution and reproduction in any medium or format, as long as you give appropriate credit to the original author(s) and the source, provide a link to the Creative Commons licence, and indicate if changes were made. The images or other third party material in this article are included in the article's Creative Commons licence, unless indicated otherwise in a credit line to the material. If material is not included in the article's Creative Commons licence and your intended use is not permitted by statutory regulation or exceeds the permitted use, you will need to obtain permission directly from the copyright holder. To view a copy of this licence, visit http://creativecommons.org/licenses/by/4.0/.

\section{References}

Alesina A (1989) Politics and business cycles in industrial democracies. Economic Policy 4(8):55-98

Archer MS (1995) Realist social theory: the morphogenetic approach. Cambridge University Press, Cambridge

Aron R (1937) La sociologie de Pareto. Zeitschrift Für Sozialforschung 6(3):489-521

Aron R (1970) Main currents in sociological thought: Durkheim, Pareto, Weber, vol 2. Routledge, London

Berger B (1967) Vilfredo Pareto and the sociology of knowledge. Soc Res 34:265-281

Bhaskar R (2008) A realist theory of science. Routledge, London

Bobbio N (2001) Saggi sulla scienza politica Italiana. Laterza, Roma-Bari

Bonmassar M (2019) Diritto e razza: gli italiani in Africa. Armando Editore, Roma

Bouvier A (2012) Pareto, Mill and the cognitive explanation of collective beliefs: unnoticed "middle-range theories" in the Trattato. In: Femia JV, Marshall AJ (eds) (2012) Vilfredo Pareto: beyond disciplinary boundaries. Ashgate, Farnham

Breznitz D, Ornston D (2018) The politics of partial success: fostering innovation in innovation policy in an era of heightened public scrutiny. Socio Econ Rev 16(4):721-741

Croce B (1923) Introduzione. In: Mosca G (ed) Elementi di scienza politica. Laterza, Bari

Dalziel P, Higgins J (2006) Pareto, parsons, and the boundary between economics and sociology. Am J Econ Sociol 65(1):109-126

Drochon H (2020) Robert Michels, the iron law of oligarchy and dynamic democracy. Constellations 27(2):185-198

Elster J (1960) Alexis de Tocqueville, the first social scientist. Cambridge University Press, Cambridge

Elster J (1983) Sour grapes. Cambridge University Press, Cambridge

Elster J (1989) Nuts and bolts for the social sciences. Cambridge University Press, Cambridge

Evans PB (1995) Embedded autonomy: states and industrial transformation. Princeton University Press, New Jersy

Ginzburg C (2003) Machiavelli, l'eccezione e la regola. Linee di una ricerca in corso. Quad Stor 38(1):195-214

Ginzburg C, Biasiori L (2018) A historical approach to casuistry: norms and exceptions in a comparative perspective. Bloomsbury Publishing, London
Hedström P, Swedberg R (1996) Social Mechanisms. Acta Sociologica 39(3):281-308

Hirschman AO (1958) The strategy of economic development. Yale University Press, London

Hirschman AO (1991) The rhetoric of reaction. Harvard University Press, Cambridge

Hunter M (2002) Rethinking epistemology, methodology, and racism: or, is White sociology really dead? Race Society 5(2):119-138

Jeynes WH (2011) Race, racism, and Darwinism. Educ Urban Soc 43(5):535-559

Majone G (1989) Evidence, argument, and persuasion in the policy process. Yale University Press, London

Marchionatti R, Mornati F (2020) Pareto's Trattato di Sociologia Generale: a behaviourist ante litteram approach. Camb J Econ. https:// doi.org/10.1093/cje/beaa044

Marsh D, Furlong P (2002) A skin not a sweater: ontology and epistemology in political science. In: Marsh D, Stoker G (eds) Theory and methods in political science, vol 2. Macmillan Education UK, London, pp 17-41

Mazrui AA (1968) From social Darwinism to current theories of modernization: a tradition of analysis. World Politics 21:69

Merton RK (1949) On sociological theories of the middle range. The Free Press, New York

Mornati F (2006) An analytical-epistemological reconstruction of the genesis of Pareto's Manuale di economia politica. Int Rev Econ 53(4):579-591

Mornati F (2018) Vilfredo Pareto: an intellectual biography, vol I. Palgrave Macmillan, Cham

Mosca G (1953) Elementi di scienza politica. Laterza, Bari

Panebianco A (2009) L'automa e lo spirito. Il Mulino, Bologna

Pareto V (1896) Corso di economia politica. Utet, Torino

Pareto V (1906) Manuale di economia politica. Società Editrice Libraria, Milano

Pareto V (1964) Trattato di sociologia generale, vol 2. Edizioni di Comunità, Milano

Pareto V (2018) L'ignoranza e il malgoverno. Lettere a "Liberty," Macerata

Pawson R (2013) The science of evaluation: a realist manifesto. Sage, London

Pawson R, Tilley N (1997) Realistic evaluation. Sage, London

Piano N (2019) Revisiting democratic elitism: the Italian school of elitism, American political science, and the problem of plutocracy. J Polit 81(2):524-538

Popkin RH (1973) The philosophical basis of eighteenth-century racism. In: Pagliaro HE (ed) Racism in the eighteenth century. Press of Case Western University, Cleveland, pp 245-262

Powers CH, Hanneman RA (1983) Pareto's theory of social and economic cycles: a formal model and simulation. Sociol Theory 1:59-89

Rogers JA (1972) Darwinism and social Darwinism. J Hist Ideas $33: 265-280$

Samuels WJ (1974) Pareto on policy. Elsevier, Amsterdam

Schumpeter JA (1944) Capitalism, socialism and democracy. Routledge, London

Sebastiani S (2013) The Scottish enlightenment: race, gender, and the limits of progress. Springer, New York

Tarde G (1886) Reviewed work: les problèmes de l'histoire by Paul Mougeolle. Revue philosophique de la France et de l'Étranger. Presses Universitaires de France, France, pp 647-652

Publisher's Note Springer Nature remains neutral with regard to jurisdictional claims in published maps and institutional affiliations. 